\title{
15 \\ DISASTER RISK MANAGEMENT IN THE SDG ERA
}

\author{
Vijayalakshmi Vadivelu
}

\section{Introduction}

Frequent natural disasters severely impact poorer sections of the population and exacerbate socio-economic vulnerabilities and reversing development gains. Over the past decade, more than 1.5 billion people have been affected by disasters that have cost at least US\$1.3 trillion - and disasters have compounded existing problems of poverty and inequality and have reversed development gains. Overall losses from natural disasters in 2019 came to US $\$ 150$ Billion. ${ }^{1}$ According to the Sendai Monitor, while there is a marginal decrease in the number of people affected in 2019 , there is an increase in the human loss as well as economic cost attributed to disasters in relation to global gross domestic product. ${ }^{2}$ These numbers are only the tip of the iceberg, as they are comprised of estimates of the replacement value of the physical infrastructure damaged or lost; the systemic impacts on human development are much larger. Progress towards achieving the Sustainable Development Goals (SDGs) is challenged in many countries by losses from disasters triggered by natural hazards. Even in regions where a comparatively smaller number of disasters have occurred, the economic impact has been significant. Countries with medium to low levels of income and weaker governance have been particularly vulnerable. Reducing disaster risk is therefore critical to poverty reduction and sustainable development. Although government mechanisms and systems to respond to disasters are critical, resilience to disaster risk must be integral to development planning processes.

Drawing on the evaluations of the United Nations Development Programme (UNDP), programme at the global and national level carried out by the Independent Evaluation Office of UNDP, this chapter revisits the disaster risk reduction efforts, progress and challenges since the adoption of the SDGs and Sendai Framework and discusses UNDP's contributions at the national level. ${ }^{3}$ This chapter examines 
integrated approaches to addressing disaster risk and vulnerability reduction in development programming. The chapter draws on the country programme evaluations as well as the conclusions and lessons based on the global "Evaluation of UNDP Support to Poverty Reduction in the Least Developed Countries," "Evaluation of UNDP Contribution to Disaster Prevention and Recovery." 4 These evaluations paid particular attention to the challenges posed by climate change in increasing natural hazards and the need for a more coordinated approach to adaptation. After a brief introduction, this chapter discusses how national governments and the international community have attempted to respond to these challenges. This is followed by the section on the approach and methodology used by the evaluations, followed by a discussion of the UNDP programme. The findings section analyses UNDPs contribution to disaster risk reduction, enabling linkages to poverty reduction and climate change adaptation and addressing multiple crises. The last section presents conclusions and selected recommendations that are relevant to other agencies and governments working in the area.

\section{Poverty, vulnerability and disaster risk}

Losses from disasters that are triggered by natural hazards significantly reverse development gains in many countries. ${ }^{5}$ The economic cost of disasters on development interventions and human development varies widely. Several studies and assessments have established that disasters heavily affect the poor in developing countries and that disaster risk is fundamentally associated with poverty levels. ${ }^{6}$ The adverse effects of disasters on social investments, particularly in health and education, and investments that provide employment and income are considerable. Besides short-term effects such as direct economic losses, disasters affect long-term human development and human security.

The low resilience of the poor is further undermined by weak or absent socialprotection measures and the low prevalence of disaster insurance in most countries. While urban and rural areas are equally affected by disasters, poverty translates into disaster risk because of the vulnerability of rural livelihoods. ${ }^{7}$ The diversity in the structure of rural societies and economies and their interactions with the environment make livelihoods more susceptible to disasters. Another factor that increases risks from natural disasters in poor rural areas is the lack of safe housing, infrastructure and public services (UNDP 2004; United Nations International Strategy for Disaster Reduction [UNISDR] 2009a; UNDP 2015). The key vulnerability factors that contribute to mortality risk are low GDP per capita and remoteness of location.

Annual exposure to GDP losses is high for cyclones and storms of medium intensity, as is nationally reported disaster loss. Destruction in the housing sector usually accounts for a significant proportion of direct economic loss in disasters. The economic losses and the number of people affected due to natural disasters are increasing at a rapid rate, faster than risk reduction can be achieved (Rodriguez, J, et al. 2009; UNISDR 2009a; UNDRR, 2019). Considerable evidence suggests that the impact on national economies adversely affects social investments, particularly 
in the areas of health and education and in areas that contribute to employment and income generation. Although disaster risk has been identified as an investment priority for achieving the SDGs, more systematic efforts are required. Though governments often prepare for worst-case disasters, recurrent small- and mediumscale disaster risks are generally insufficiently addressed. Furthermore, wellmeaning efforts to increase social and economic development may inadvertently increase disaster risk unless disaster risk reduction considerations factored into all development-related investments. Disaster risk reduction as a governance issue is still emerging in both government policy and planning.

There are increasing concerns about the implications of climate change. The consequences of an increase in either slow- or rapid-onset disasters caused by extreme weather events are enormous and threaten agricultural production, food and water security, public health and peace and security. Among many impacts, climate change will increase the frequency and intensity of weather-related hazards, such as floods, cyclones and droughts. ${ }^{8}$ Other potential effects of climate change, such as ecosystem degradation, reduced availability of water and food, energy crises and changes in livelihoods will increase communities' vulnerability to natural hazards (Prasad et al. 2009).

Developing countries will be hardest hit by climate change; consequently, they suffer from increased disaster risk. Climate change will have implications for most regions, but some will be more affected than others, such as East Asia and the Pacific and the Caribbean, which are already vulnerable to natural disasters and extreme climatic events. ${ }^{9}$ An analysis of the climate risk index and extreme weather events from 1998 to 2007 indicates that the top ten countries hardest hit include Bangladesh, the Dominican Republic, Haiti, Honduras, India, Mozambique, Nicaragua, the Philippines, Venezuela and Viet Nam.

Disasters affect women and men differently. It is widely documented, for example, that women are particularly vulnerable to natural hazards and that mortality from disasters is high among them. Gender inequalities in accessing resources, capabilities and differential opportunities place women at a disadvantage, making them more vulnerable to the impact of disasters (Bhatt 2005; Neumayer and Plümper 2007). Although attention is paid to women as a disadvantaged group, gender perspectives have yet to be systematically integrated into disaster-related interventions.

Lack of attention to gender is a recurring feature in disaster response despite the fact that individually and collectively, governments, international development organizations and donor agencies have made strong commitments to gender equality and women's empowerment. Yet despite such efforts, the operationalization of gender-responsive policies and practices has been ad hoc and inconsistent (UNISDR, UNDP and ICUN 2009). Reporting by the Hyogo Framework for Action (HFA) indicates that although an increasing number of governments are recognizing the importance of gender issues in national disaster risk reduction efforts, ${ }^{10}$ meaningful progress has yet to be made. 


\section{National initiatives}

After a decade of concerted effort to achieve the MDGs, and as we approach the mid-point of the ten-year HFA, definite progress can be seen in terms of government action to address disaster-related issues. First, more people are recognizing that disasters can be prevented and disaster impacts can be mitigated. Second, various actors at the national, regional and global levels have acknowledged the added value in coordinating disaster-related interventions. Third, there are positive indications that the perspectives of agencies working on disaster support and those working on long-term development are converging. Fourth, recognition is growing that reducing disaster risk is a development issue - one that requires addressing the underlying risk factors that make people and their livelihoods more vulnerable to both slowand rapid-onset disasters.

The 2009 Global Assessment Report on Disaster Risk Reduction (UNISDR 2009a) appraised the progress made in implementing the HFA. The findings indicate that, globally, national efforts have focused on HFA Priorities 1, 2 and 5: strengthening policy, legislation and institutional frameworks, and on building capacities for disaster preparedness, response, risk assessments and early warning. The effort was found to be less adequate in HFA Priorities 3 and 4: using knowledge, education and outreach programmes to stimulate a culture of disaster resilience and addressing the underlying factors related to social, economic and infrastructure development across rural and urban contexts.

Challenges remain in compiling comprehensive risk assessments in a way that can inform disaster risk reduction and link early warning with disaster preparedness and response planning. Efforts also fell short in using national information to inform local action. One reason why progress in HFA implementation has been limited is that the scale of resources available for disaster risk reduction falls well short of what is needed to ensure the resilience of nations and communities (United Nations General Assembly [UNGA] 2008). Although the HFA pays attention to broader institutional frameworks and policies for risk reduction, the response to major disasters indicates the need for better and more suitable administrative systems and procedures (e.g. the Myanmar earthquake, Gujarat earthquake and the Asian tsunami).

Limitations were also found in the extent to which national development policies and plans included dimensions of disaster risk reduction. An evaluation review of 67 poverty-reduction strategy papers in 2012 indicated that only $20 \%$ discussed in detail disaster risk reduction, 25\% did not mention disaster risk at all, and 55\% mentioned only the relationship between disaster risk and poverty without providing concrete recommendations for addressing it. Countries that have integrated disaster risk reduction into their poverty-reduction strategy papers include Bangladesh (2005), Malawi (2006), Mozambique (2006) and Viet Nam (2006). Since the adoption of Sendai Framework, there is an improvement in incorporating 
disaster and climate risk factors in national strategies. In terms of the global targets of the Framework, 59 out of 195 countries have initiated efforts to address disaster risk. ${ }^{11}$ However such efforts are not sufficient for addressing significant and increasing climate and disaster risks.

\section{Intergovernmental response}

Since 2015 the landmark intergovernmental agreements, the Sendai Framework for Disaster Risk Reduction, ${ }^{12}$ the Paris Agreement ${ }^{13}$ and the Sustainable Development Goals ${ }^{14}$ have set the agenda for reducing risks associated with all hazards and unsafe conditions. These agreements are significant as they put risk reduction as central to the development agenda, as integral to sustainable and equitable economic, social and environmental development. The interlinkages between these agreements are equally significant. Effective disaster risk management and reducing vulnerability to natural hazards are key to progress on SDGs. An additional dimension to risk reduction is managing the interrelated vulnerabilities compounded by climate change. The Paris agreement to combat climate change and adapt to its effects is therefore fundamental to the disaster risk reduction agenda. Climate change intensified disaster risks with the increase in the weather and climate hazards and related vulnerabilities, particularly through ecosystem degradation. The three intergovernmental agreements present an opportunity to ensure that risk management became central to development policy and planning and for efforts to reduce disaster losses.

Although most countries are signatories to the Sendai Framework, integrating environment management, climate change adaptation and disaster risk reduction has yet to manifest in practice. Besides, greater regional and global collaboration is a necessity for greater accountability of risk-causing countries, because the countries that will be most affected by climate change have done the least to contribute to it. Greater coordination between disaster risk reduction, development and climate change actors while recognized as critical for responding to the humanitarian challenges of climate change and addressing the root causes of vulnerability concrete actions are evolving but not at a faster pace.

Given the slow progress of the Sendai framework after five years of its adoption, it is important to address the limitations of the previous iterations of the Framework, the HFA. A key issue the intergovernmental efforts should address is the interface of multiple crises and their interlinkages. Disaster risk cannot anymore be seen in isolation from climate-related impacts. Also, climate impact needs new institutional systems and process at the national level that can adapt to new types of risks. The absence accountability mechanism is another issue that is slowing Sendai framework progress.

There has been an international governmental consensus on the importance of gender equality in disaster risk reduction which was reflected in the formulation of the Sendai Framework. In its guiding principles, the Framework emphasizes that disaster risk reduction policies and practices should be informed by gender, age, disability and cultural perspective. Besides, the SDGs provide the necessary thrust 
on gender quality as a cross-cutting principle for all the goals. Global advocacy on the importance of gender in disaster risk and vulnerability reduction while gained momentum is yet to translate into concrete policies at the national level.

\section{Approach, data and methods}

Drawing from an analysis of key concerns in prevention and recovery and UNDP strategic documents on support to countries affected by natural disasters and climate impacts, the evaluation approach acknowledges the multiple dimensions of disaster risk reduction. Reducing disaster risk and vulnerability is a development issue and an important factor in achieving the SDGs. The enormous consequences of disasters for human development, poverty reduction and economic growth necessitate effectively managing disaster risk as an integral part of development planning; an integrated approach during recovery and reconstruction can be a way to reduce future risk. Similarly, links between disaster risk, climate change and environmental management make an integrated national planning and programming approach essential to risk reduction and long-term recovery. Addressing disaster risk reduction and climate change adaptation is critical to minimizing development reversals and reducing poverty and vulnerability, although strategies to accomplish this are still emerging.

Strengthening national capacities, particularly governance and coordination mechanisms, is critical to responding to disasters and reducing risk. Prevention and recovery work provides an opportunity to go beyond restoring things to the way they were - if done strategically, it can enable affected communities to achieve even greater levels of resilience. This also includes systematically integrating gender into development frameworks, which in many instances influences how gender dimensions are addressed in disaster risk reduction and recovery.

The questions of the evaluation of disaster management support related to the standard evaluation criteria of relevance, effectiveness, efficiency and sustainability of UNDP work, including its responses to challenges posed by disasters. The poverty reduction in least developed countries (LDCs) evaluation used a set of criteria, namely UNDP programme positioning, strengthening national capacities, contribution to global policy and advocacy, convening role and enabling partnerships. Areas covered in the evaluation are that of relevance for disaster reduction in the poverty-environment nexus and addressing multiple crises. The evaluations used a variety of methods and data to build evaluative evidence for answering its questions.

The evaluations included case studies of twenty-four countries. ${ }^{15}$ Country case studies entailed a comprehensive document review, stakeholder analysis, consultations and interviews. At the country level, a stakeholder analysis was carried out to identify organizations working in the area of disaster management, those involved in development support and those engaged in pertinent aspects of environmental management, climate change adaptation and coastal area management. The consultations involved a wide range of development stakeholders, including government officials, international agencies, UNDP programme donors and international and national non-governmental organizations (NGOs). 
Structured and semi-structured interviews and focus group discussions were used to collect primary data. The method took into consideration country-level data limitations, the delineation of different phases of support, the linking of different levels of analysis and varied timeframes and the systematic validation of causality, linking process to results. This evaluation method ensured that different stakeholders' perspectives were captured and that the findings could be triangulated. Other sources of evidence were used to either substantiate findings or further explore the country case studies, thus ensuring that they were credible and robust.

\section{UNDP response}

UNDP recognizes the importance of disaster risk management to poverty reduction and sustainable human development and has, over the past four decades, supported interventions in the areas of prevention, response and recovery. The aim of such programmes has been to strengthen national capacities to prevent (reduce risk) as well as to respond to natural disasters. More specifically, UNDP provides assistance to develop government capacity to manage recovery and to ensure renewed progress towards the MDGs and later SDGs while reducing vulnerability to future disasters. Programming in key areas of development, an extensive national presence and partnership with governments and other national stakeholders provides UNDP with a unique opportunity to address disaster risk as a development challenge and to focus recovery on reducing vulnerabilities.

The Strategic Plans of UNDP (for the periods 2008-2011, extended to 2013, 2014-2017 and 2018-2021) ${ }^{16}$ strongly emphasizes strengthening the national capacities needed to manage recovery while reducing vulnerability to future disasters. The key areas of UNDP support are as follows: strengthening policies and institutional capacities, legal and regulatory frameworks, assessment and analysis, sectoral strategies for disaster risk reduction, risk-informed development planning and budgeting, disaster recovery governance, community-based rural and urban risk management and gender equality informed disaster management. A keystone of UNDP's approach has been the provision of long-term and sustained support which has been instrumental in accompanying countries through the many ups and downs in their endeavours to strengthen their risk governance capacities and build resilience. UNDP's coverage has grown significantly - from programmes in 34 countries in 2000 to 125 countries in 2020, with over 1500 projects addressing different areas of disaster management. While UNDP has supported large, nationallevel disaster management programmes over the years (e.g. in Bangladesh, India, Indonesia and Pakistan), other countries have smaller programmes of shorter duration, concentrated at the subnational level.

Resilience approach to disaster risk reduction and climate change adaptation underpins the UNDP approach, for ensuring that development gains are resilient to the impacts of disasters and extreme weather events. UNDP strategic documents highlight the importance of addressing disaster-related issues and their linkages to climate change adaptation and human and economic development. UNDP's 
support for sustainable development emphasizes the importance of protecting the environmental base and reducing disaster risk as necessary for long-term poverty alleviation.

UNDP sees its role as supporting countries in their efforts to resume public service delivery as early as possible in the post-disaster period. During the humanitarian phase, UNDP aims to assist national governments set up aid coordination mechanisms and strengthen the capacities of local administrations to manage recovery processes. Another objective is to use its global knowledge and experience with disaster risk reduction to engage governments and other partner institutions to develop capacities for recovery and reducing future disaster risks.

Guided by the UN Convention on the Elimination of All Forms of Discrimination against Women, ${ }^{17}$ SDGs and other intergovernmental agreements, UNDP corporate strategies place considerable emphasis on promoting gender equality in all of the organization's initiatives and its support to the government. When necessary, this includes specific women's empowerment initiatives. ${ }^{18}$ The commitment to achieving the SDGs provided further impetus for a gender equality focus in programme support. The UNDP commitment in this area is reflected in its global gender strategies, the Gender Action Plan (2006-2007), the Gender Equality Strategies (20082013; 2014-2017; and 2018-2021) ${ }^{19}$ and the Eight-Point Agenda for Women's Empowerment and Gender Equality in Crisis Prevention and Recovery, which provide a framework for all UNDP activities (UNDP 2007b; UNDP 2008a). Gender Equality Strategies acknowledge women's increased vulnerabilities during conflict and disasters. It also recognizes that giving attention to the differing needs of women and men maximizes the potential for full community recovery.

At the country level, areas of thematic engagement include institutional and legislative systems, community-based disaster risk management, support to national governments to establish risk reduction and climate risk management. In recovery efforts, UNDP focused largely on restoring normalcy following a crisis, transitioning effectively from crisis to development, and using recovery work as an opportunity to promote resilience to disasters and climate shocks. Such efforts have focused on strengthening governance structures and policies for better disaster management (e.g. prevention, mitigation and response, and providing post-disaster support in social and economic areas).

In the last decade, several rapid-onset disasters have taken place, both those that are large in scale and annually recurrent events of smaller intensity. UNDP supported responses to all major recent disasters. Support for recovery consisted mainly of post-disaster needs assessments, support to livelihoods and housing, coordination (involving both NGOs and governments) and strengthening government capacities.

Drought-related mitigation and recovery were not included in the UNDP disaster management programme due to the way programmes are categorized in UNDP programme frameworks. Drought and floods are considered as a consequence of climate change, affecting livelihoods and development in general. These are largely addressed as part of poverty reduction and climate change adaptation programmes. UNDP recognizes that climate change is a major threat to sustainable development 
and has provided support to this area for the past three years. Similar to droughtrelated mitigation, climate change adaptation is under a different programme unit of UNDP, although the inter-linkages with disaster risk reduction are relevant from the point of achieving programme results.

\section{Findings}

The UNDP programme strategy acknowledges disaster risk reduction as an important factor in reducing poverty and vulnerability and achieving the SDGs. In its publications, UNDP advocates giving greater importance to disaster risk reduction in achieving development results. In the last ten years, UNDP has actively participated in debates to further consensus on global policies to strengthen links between climate change adaptation and disaster risk reduction. Sustained commitment is reflected in closer integration of disaster risk reduction with other UNDP priority areas (e.g. poverty reduction, governance and adaptation to climate change). The following sections discuss areas where UNDP contributions, its comparative advantage and programming constraints.

\section{Working with national systems}

Governments are making important efforts to fulfil their commitments to the Sendai Framework (and its predecessors) and other conventions, and this has provided the impetus for formulating related legislation and policies. UNDP responded to such needs at the national level and supported governments establish institutional and legal frameworks for disaster management. UNDP support in this area was crucial in creating an enabling environment for policy formulation and in setting up key institutions for disaster risk management. Out of 58 country programme evaluations analysed, UNDP played a key role in policy formulation in 31 countries; in 27 countries, UNDP contributed to creating an enabling environment for disaster risk management.

Contribution to the policy discourse on sustainable livelihoods was evident in UNDP's engagement in the shaping of the SDGs and integration for climate change adaption issues in the Sendai Framework for Disaster Risk Reduction. UNDP remains a leading United Nations provider of environmental protection support at national and local levels and has been a significant provider of technical support to the government during global and regional negotiations on environmental issues such as climate change, biodiversity loss and water pollution. UNDP advocated for environmental budgeting by supporting efforts to engage parliament, creating committees on poverty-environment issues and engaging high-ranking government officials in poverty-environment projects. Most importantly, tracking budgets and expenditures by analysing budget data according to special issues, povertyenvironment concerns and climate change adaptation has enabled better advocacy aimed at increasing budget allocations for poverty-environment mainstreaming, as well as to raise awareness on related issues. With a wide-ranging climate change 
programme in place, UNDP has played a prominent role in regional and global policy debates on global climate change in support of countries preparing for and responding to the 2015 Paris Agreement.

UNDP has been more effective in enabling sector-specific support, particularly when establishing disaster management institutions and policies or pilot interventions in disaster preparedness. Although in many ways this reflects the larger, national-level challenge, UNDP has had limited success in addressing issues related to the integration of disaster risk reduction in development planning and in strengthening government capacities in intergovernmental coordination for disaster risk reduction. UNDP responded to governments' expressions of interest to mainstream disaster risk reduction in Honduras, for example, and at the state level in Mexico. However, this was not often given adequate priority in UNDP programming. ${ }^{20}$ In countries such as Colombia, the roles, responsibilities and accountability at different levels of government and among institutions responsible for disaster risk management could be better harmonized.

Increasingly, governments are recognizing the links between disaster risk reduction, poverty reduction and development; efforts are being made to address these links. For example, in Mexico the government is taking measures to include disaster risk reduction in social development programmes. In the Maldives, disaster and climate risk reduction are considered critical issues and are fully integrated into development planning. UNDP's support in Bangladesh provides an example of a typical UNDP programme at the country level in the context of multiple crises. In Bangladesh, as part of the disaster risk reduction, UNDP's Early Recovery Facility initiated a pilot short-term employment project linked to the rehabilitation of community infrastructure and solid waste management. Solid waste management, ecosystem restoration and mapping of social risks are areas of UNDP's support. Each of these initiatives is critical to addressing the vulnerabilities of the host communities as well as the Rohingya refugees in Cox's Bazaar. UNDP played a strategic role in disaster risk reduction in the refugee areas in managing hazards and risks. This support is widely perceived as critical for the local government. Advisory role of UNDP in disaster risk reduction enabled work on resilience in the Rohingya refugee camps and training humanitarian actors on how to manage disasters and extreme weather. UNDP's Early Recovery Facility in the country office facilitated this strategic contribution within the refugee camps, in host communities and preparedness support to the district government. UNDP provided disaster risk reduction technical support to the JRP agencies, a critical requirement in the region with refugees. A series of socio-economic impact assessments and the initiation of a district development planning process have enabled a more structured local response to the crisis. An area that needs further attention is the consolidation of activities by various agencies in the areas of employment and livelihood and local services.

Despite commitments of the countries to international agreements such as Sendai Framework here remain significant challenges in integrating disaster and climate risk reduction into national plans and programmes. The progress remains slow 
in integrating disaster risk reduction into national development planning in most countries, particularly in the allocation of budget for risk reduction. The same can be said about contributing to implementation in countries where risk reduction is already a development priority.

UNDP strategy acknowledges disaster risk reduction as an important factor in reducing poverty and vulnerability and achieving the SDGs. Although disaster risk reduction is prioritized as a programme area in many countries, UNDP has paid sparse attention to its interface with poverty reduction. Despite the organizational commitment, closer integration of disaster risk reduction with other UNDP priorities, such as poverty reduction, governance and adaptation to climate change, is progressing in some country programmes has not been given sufficient priority in many others. UNDP poverty reduction initiatives are yet to include a risk-reduction dimension, although there are exceptions. A disaster risk reduction or climate change adaptation component in poverty reduction initiatives is seen as an expendable, additional cost. A few exceptions were found, which offer important lessons for strengthening synergies among complementary areas of the UNDP programme, government and other development agencies. In Mexico, for example, integrating disaster risk reduction components into projects significantly contributed to sustaining local-level development investments. Similar results are evident in Bangladesh in a community-based poverty-reduction programme that incorporated disaster preparedness and risk reduction. In Honduras, disaster risk reduction is addressed as a governance issue.

A notable change is the UNDPs resilience approach, introduced in 2008, is enabling a shift towards vulnerability reduction in UNDPs programme support. Resilience approach, with long-term focus, is gathering momentum in UNDPs crisis response. The integrated framework promoted by the 2017 Strategic Plan is enabling a shift in UNDPs programmes, particularly in establishing linkages between its programme response in the areas of poverty reduction, climate change adaptation and disaster risk reduction. Similarly, disaster risk reduction as a governance issue is emphasized in UNDPs support, particularly in enabling policies and governance structures.

In several LDCs, climate impacts have increased the frequency of droughts, floods and cyclones, and the national policy response does not reflect the severity of the issue. Promoting approaches to improve food security and sustainable development linkages through adaptation strategies contributed to livelihoods change processes at the subnational level. Climate-related disaster risk reduction initiatives that have livelihood resilience components were aligned with adaptation efforts, complementing government priorities to reduce poverty and vulnerability to risks and improving food security (e.g. in Mozambique). Cash for work activities supported by UNDP provided income during disaster recovery on a short-term basis (Haiti and Nepal). While debris removal provided employment immediately after disasters, solid waste management in post-disaster situations was critical, with consequences for enhancing community income and living conditions. 


\section{Addressing multiple and interlinking crises}

While there are conducive organizational policies to promote resilience, intersecting elements of crises and their linkages are yet to be prioritized in implementation. The LDCs, for example, have experienced natural and climate-related disasters (both rapid-onset disasters and droughts), health pandemics and conflict. To better understand the scale of the problem, over half of the LDCs are subject to multiple crises including recurrent disasters, in addition to poverty, the volatility of commodity prices and aid flows, and severe structural challenges. The macroeconomic impact of these episodes of extreme drought and flooding is not only significant by itself but exacerbates the impact on poverty in the context of conflict or early conflict recovery. At any given point in 10-12 LDCs, UNDP programmes are implemented in the context of multiple fragilities. ${ }^{21}$ UNDP has programmes in the areas of climate-resilient agriculture and livelihoods, inclusive growth and incomegeneration initiatives, economic revitalization and peacebuilding; it is also progressively adopting ways to improve resilient development. Despite the range of support provided, opportunities were not used to enable an integrated approach to address intersecting linkages between drought and poverty or drought-conflict and poverty.

Poverty and drought can potentially become drivers of conflict when attention is not paid to nexus issues. In Mali, while each of UNDP's initiatives (in the areas of poverty, crisis and environment) is relevant individually for the development priorities of the country, opportunities were lost in enabling a focus on linkages between multiple fragilities, such as food security, resilience and vulnerability, and conflict. While the humanitarian situation is fragile, the socio-political instability in the northern region of the country, coupled with recurrent floods and pressures due to the events in the Central African Republic and northern Nigeria, have impacted the lives and livelihoods of over 3 million people. UNDP is better positioned to raise the importance of balancing development and crisis support and to advocate for more integrated policies, instead of getting subsumed in the larger conflictcentred development discourse at the country level.

UNDP's resilience approach aims to reduce development risks, prevent crises, avert major development setbacks and promote human security. This approach provided an impetus to closely align climate change adaptation and disaster risk reduction frameworks in livelihood support, and to position policy advice on these intersecting areas with a risk-sensitive approach to poverty reduction. Despite these policies, UNDP's poverty reduction efforts in the context of multiple crises are yet to address the combined effect of multiple crises and resulting vulnerabilities.

\section{Climate change adaptation and disaster risk reduction}

Climate change adaptation programmes of UNDP evolved in the past two decades and several interventions that were part of the poverty reduction and environment area had comparable goals. UNDP has aimed to address climate change adaptation as a development issue and as a factor in achieving the MDGs and later SDGs 
provided the necessary thrust. With increased recognition of the links between environment and climate change adaptation and disaster risk reduction, efforts have been made within UNDP to explore possible synergies in programming. There has been progress in consolidating climate change adaptation and disaster risk reduction teams. There is scope for improving synergies between programmes in these two areas. UNDP is taking measures to strengthen synergies to demonstrate through its programmes the critical urgency of integrating disaster and climate risk reduction.

The countries included in the evaluation have different levels of vulnerability to climate change, ranging from Colombia, India and Mexico (where climate change is one of many challenges), Tanzania (where climate change has had a significant impact on agriculture and livelihood), to the Maldives (where it threatens the very future of the country). In all countries, the anticipated impacts of climate change will likely be superimposed over existing climate-related disasters. This superimposition is particularly true for countries with a large population living in coastal areas and arid regions. Overall, UNDP adaptation projects are designed to decrease vulnerability to climate change impacts, although there is considerable scope for integrating it in poverty-reduction interventions. Some of these constraints of establishing linkages are also due to the funding mechanisms that require specific outcomes.

In the Maldives, the disaster risk reduction and adaptation links are well established by the government through its development plan - but such an example is more of an exception. In most countries, environment, climate change adaptation and disaster risk reduction activities tend to be spread among different government agencies. Besides, national frameworks for implementing the intergovernmental commitments are spread across different ministries, with responsible for each activity.

Coordination between disaster risk reduction and climate change adaptation has been limited in most countries despite intersectoral taskforces. Although governments acknowledge the need for synergies between the two areas, both at the conceptual level as well as in programme implementation, concrete efforts towards this end are rare. UNDP is supporting efforts to addresses the policy, programming and partnership issues that integrated programming would necessitate. Further, the current climate change adaptation and disaster risk reduction frameworks do not lend themselves to an integrated approach.

The severity of recent disasters has pushed the issue of climate change adaptation to centre stage, with direct implications for UNDP programming. Through its assistance to national governments both before and after disasters, coupled with extensive country-support mechanisms covering the environmental protection aspects of climate change, UNDP is well positioned to help countries develop effective adaptation strategies.

UNDP considers its responses to slow-onset disasters (e.g. drought) to be an aspect of poverty reduction and sustainable environment support, and are therefore not under the purview of disaster risk management. The impact of climate change is likely to blur the boundaries between slow- and rapid-onset disasters in the future and measures for better coordination among programme areas are critical. Support to prevent or mitigate slow-onset disasters entails a different approach and 
alternative strategies. It will require closer coordination with poverty reduction and environment programmes and new partnerships with different government agencies and stakeholders.

UNDP's initiatives in climate change adaptation have been critical for reducing the vulnerability of LDCs to climate change shocks, strengthening their resilience, and mainstreaming sustainable development into national development policies and strategies. Managing over one-third of GEF, GCF and other vertical green funds, UNDP is well situated to enable a national focus on factors that facilitate sustainable livelihoods. Environment and climate change adaptation programmes have consistently incorporated or promoted a sustainable approach to the environment as well as livelihoods by linking community income generation and natural resource management interventions. UNDP has had some success pursuing a greater consideration of poverty and livelihoods within the framework of its support to UN conventions, both climate change and disaster risk reduction in the past five years, which need further consolidation. UNDP should not only further leverage this work for a global policy engagement but also increase the scale of such programmes.

\section{Promoting gender equality}

UNDP has taken policy measures to ensure greater attention to gender equality and women's empowerment in programming. The mandatory allocation of $15 \%$ of funds for gender-related activities in crisis-related programmes (both conflict and disaster) is a measure unique to UNDP that operationalizes gender policy. At the global and regional levels, UNDP contributed to advocacy and publications to make disaster prevention and recovery more gender sensitive.

A few country programmes (e.g. Mexico) outlined gender equality as a priority area and set up a gender unit to support government efforts and to integrate gender priorities within the UNDP country programme. Important efforts were also made to prepare training modules for creating awareness and integrating gender-related issues into disaster risk reduction. Manuals were produced for regional programmes in South Asia and Mexico. Coordination with other agencies, particularly NGOs, was instrumental in ensuring that a gender perspective was integrated into all aspects of recovery work. In Indonesia, UNDP supported the government to develop strategies for integrating gender in recovery and reconstruction activities. Gender-disaggregated recovery indicators developed by UNDP at the country level were key to including gender and women's empowerment as a cross-cutting dimension in recovery programmes. UNDP contributed to efforts to ensure that women had a say in post-disaster housing and were joint owners of the assets provided as part of recovery programmes in Bangladesh, India, Indonesia and Sri Lanka.

Attention paid to gender-related issues did not reflect UNDP's commitment to accelerating gender equality. Although programmes were targeted at women and efforts were made to ensure their participation in disaster prevention and recovery, gender issues were not addressed systematically in programme planning and 
implementation. Constraints in addressing gender concerns in disaster risk management persist, including limited progress in dealing with gender priorities in development. While a commitment to gender equality may exist at the national level, practical measures to fulfil commitments were lacking. Reporting on progress of Sendai Framework on integrating gender perspectives in disaster risk reduction and recovery points to similar issues.

An area where there are lessons for synergies with disaster risk reduction is Development Finance Assessments (DFAs). Bangladesh (Climate Fiscal Framework) and Cambodia (Climate Change Financing Framework) have demonstrated leadership in reforming climate financing approaches and institutional arrangements, with indications of improved inter-ministerial coordination and an increasing role for and importance of ministries of finance in climate financing arrangements. In Bangladesh, based on the DFAs, the government has reformed the institutional set-up for managing development cooperation and drafted a National Policy on Development Cooperation; financing needs for the SDGs have also been estimated. Drawing upon lessons learned from Bangladesh and Cambodia on the Climate Fiscal Framework, other countries in the Asia region are developing climate financing frameworks. Such efforts have salience for disaster risk reduction financing arrangements.

\section{Building local-level capacities}

An area where UNDP has consolidation its support is strengthening local capacities in disaster management. An area where there were tangible results is the integration of disaster risk reduction in local plans, which were important particularly in the case of recurrent local level disasters. Disaster preparedness and risk reduction initiatives were implemented in more than 45 countries since 2009. Community approaches to sustainable livelihoods, natural resource management and enhancing resilience to disasters and climate change are areas where UNDP engagement has helped generate tangible local-level impacts. Women's economic empowerment received sufficient attention across programmes with contributions at the project level. Urban poverty is an evolving area of UNDP programme support that merits greater attention.

The scale and duration of such programmes varied across countries. Community preparedness initiatives were useful in strengthening local capacities. In several instances, UNDP used community programmes to demonstrate the importance of disaster preparedness and to integrate a disaster risk reduction component into local-level development interventions. In Mexico, for example, UNDP was able to scale up community-based preparedness interventions to the state level. UNDP has also been successful in informing government practices in Bangladesh and India. In India, the programme succeeded in demonstrating the importance of local-level preparedness. Other examples were also found where preparedness programmes contributed to better coping at the community level. ${ }^{22}$ 
The challenge in programming at the community level was the limited links to related government programmes. The fact that interventions were rarely institutionalized meant that they were one-off successes and failed to inform government programmes and policies. Strengthening local governments' capacities remains a challenge. There is also the risk of community programme mechanisms becoming parallel structures to local governments. With some exceptions, limitations were found in the links established among different levels of government. Excessive focus on contingency planning and preparedness and limited interventions in risk reduction weakened the possible contributions of community-based initiatives.

\section{Conclusion}

It is five years since the SDGs and the Sendai Framework have been adopted and commitments were made by countries to sustainable development and reduce the impact of natural and other disasters. Considering its cross-cutting nature, across different sectors of development, there are 25 disaster risk reduction related targets across 10 of the 17 SDGs, reinforcing the importance of addressing this challenge as part of the national development strategy. Besides, SDG 13 underscores the need to strengthen resilience and adaptive capacity to climate change for achieving sustainable development. Compared to the MDGs period, acknowledging the negative implications of disaster risk for development and poverty reduction in the international frameworks is a significant step forward. On both the SDGs and Sendai Framework, while there has been progress, the pace of it has been slow, and there remain significant gaps in achieving the objectives of the Framework. Natural hazards, both slow and rapid onset, are largely foreseeable. They provide governments and international agencies a rationale for taking prevention and preparedness measures to ensure that impacts are minimized. While an increase in the frequency and severity of recent disasters has called attention to the need for disaster risk reduction, challenges persist in taking practical measures to see it realized. Disaster recovery is generally regarded as urgent, but the focus is often limited to recovering what existed before, rather than addressing underlying vulnerabilities and future prevention. Reducing disaster risk is key to achieving objectives in poverty reduction and sustainable development.

The extent to which international agreements resulted in national policies that promote integrated approaches to development, to reduce disaster risk and enable climate change adaptation is evolving. For a resilient development, national poverty reduction efforts, particularly in the area of rural livelihoods need to systematically integrate disaster risk reduction and adaption. The role of international agencies in national disaster risk reduction as part of development support assumes importance in strengthening related policy processes.

In the area of climate-related disasters including slow-onset disasters, disaster risk reduction and climate change adaptation have similar goals, which calls for more coordinated programming at the national level. There has been increasing financing for climate change adaptation through various funding mechanisms 
further strengthened by Paris Agreement in 2016, while there remain resources challenges for disaster risk reduction efforts, which have similar goals in the area of slow-onset disasters. This highlights the importance of combined efforts in the area of adaptation and climate-related disaster risk reduction efforts, specifically integrating such efforts as part of key development strategies than as stand-alone efforts.

There is a need to strengthen institutional systems and capacities at the local level. Local governments typically lacked the authority and capacity to manage recovery programmes. Even in countries with strong national institutions, local governments were without the financial resources needed to carry out disaster risk reduction activities. Typically, the responsibilities of local governments are ill defined. Agencies such as UNDP that have a long-term presence at the country level have a pivotal position to bring risk-reduction issues into greater focus during recovery and in the development process more generally.

The lack of focus on the interface between poverty reduction, environment and disaster risk management has been compounded by several factors. The compartmentalized nature of programming has often constrained partnerships beyond disaster management agencies. Disaster management agencies in most countries predominantly addressed vulnerability from the perspective of location and physical infrastructure. Engaging only with disaster management institutions narrowed the perspective of disaster risk reduction interventions. If disaster risk management is to focus on vulnerability or poverty reduction, government institutions that have a mandate for poverty reduction, the environment, gender equality and related development issues must be involved.

There are cost implications for considering poverty reduction from the wider perspective of disaster vulnerability reduction and climate change risk, which includes incorporating a disaster risk reduction component. This also applies to recovery programmes in most countries, where integrating long-term risk reduction is not regarded as viable because of the extra costs involved. Although governments in many countries perceived the need for a more integrated approach to development planning, such efforts are at early stages. Most countries lacked a cost-benefit analysis of the advantage of vulnerability and disaster risk reduction in poverty reduction, which could inform government decisions and resource allocation. Advocacy in this area has been minimal. For example, MDG monitoring is not used as a tool to emphasize how disasters, particularly recurrent small-scale natural events, increase poverty levels and reverse development gains.

In recent years, greater attention to climate change adaptation has contributed significantly to raising awareness and understanding of the importance of addressing the interlinkages coherently, including its relationship to work on preventing and recovering from natural disasters. Interrelated policies and legislative frameworks are important from the perspective of disaster risk reduction and climate change adaptation. Aside from poverty reduction strategy papers and national development plans, policies related to climate change, environment, water management, coastal 
area/resource management, energy management, land use and urban planning are critical to a multidimensional approach to disaster risk reduction. Support for harmonizing overlapping mandates pertaining to disaster risk management and coordination among government agencies furthers policy consolidation.

\section{Notes}

1 Munich Re NatCatSERVICE database.

2 UNDRR, 2019, Sendai Monitor. https://sendaimonitor.undrr.org/analytics/ global-targets $/ 15$.

3 The Independent Evaluation Office (IEO) is charged with conducting evaluations of the relevance and performance of UNDP's work at the country, regional, global and thematic levels. The IEP reports to the UNDP Executive Board, which has requested the office to conduct evaluations of critical aspects of UNDP's work in order to ensure accountability and to achieve organizational learning. In 2018-2019, IEO carried out "Evaluation of UNDP Support to Poverty Reduction in the Least Developed Countries," and 2009-2010, the Evaluation Office carried out the Evaluation of UNDP Contribution to Disaster Prevention and Recovery. See http://web.undp.org/evaluation/evaluations/ thematic/poverty-ldc.shtml; http://www.undp.org/evaluation/thematic/par.shtml.

4 IEO, 2019. Evaluation of UNDP Support to Poverty Reduction in the Least Developed Countries. http://web.undp.org/evaluation/evaluations/thematic/poverty-ldc.shtml.

5 See GAR, 2019.https://gar.undrr.org/sites/default/files/reports/2019-05/full_gar_report. pdf.

6 See UNISDR (2009b), Harmeling (2009), Telford and Cosgrave (2006) Benson and Clay (2004), and Wisner et al. (2004).

7 See UNISDR, 2015. Disaster Risk Reduction And Resilience In The 2030 Agenda For Sustainable Development, A reflection Paper; UNISDR (2009), Assessment of Development Results in Tajikistan (EO 2009), Assessment of Development Results in Nicaragua (EO 2007), Telford and Cosgrave (2008), Wisner et al. (2004).

8 Robert Glasser (2020). The Climate Change Imperative to Transform Disaster Risk Management, Int J Disaster Risk Sci (2020) 11:152-154; Sneed, A. 2018. The next climate frontier: Predicting a complex domino effect. Scientific American. https://www. scientificamerican.com/article/the-next-climate-frontier-predicting-a-complex-domino-effect/; Prasad, et al.

9 See Harmeling (2009); UNISDR (2009a); United Nations Development Programme (2007a); IPCC (2007);WFP, IFR CRC \& OCHA (2009); and Chibber and Laajaj (2008).

10 There is no significant change in the extent to which national strategies address gender concerns in disaster risk reduction. Sendai Framework has limited information on this.

11 See https://sendaimonitor.undrr.org/.

12 Sendai Framework https://www.undrr.org/implementing-sf.

13 Paris Agreement https://unfccc.int/process-and-meetings/the-paris-agreement/ the-paris-agreement.

14 https://www.un.org/sustainabledevelopment/sustainable-development-goals/.

15 For the disaster management evaluation following country case studies were conducted: Colombia, Fiji, India, Indonesia, Madagascar, Maldives, Mexico, Mozambique and Myanmar; and for the Poverty reduction in the LDCs evaluation 15 case studies were conducted in Angola, Comoros, Ethiopia, Madagascar, Malawi, Mali, Senegal, Uganda, Djibouti, Sudan, Yemen, Cambodia, Lao PDR, Samoa, Haiti. 
16 UNDP (2008a) Draft Strategic Plan, 2008-2011:Accelerating Global Progress on Human Development (extended to 2013); UNDP (2013), Changing with the World. UNDP Strategic Plan: 2014-17; UNDP,UNDP Strategic Plan 2014-2017', UNDP (2018). UNDP Strategic Plan, 2018-2021.

17 Adopted in 1979 by the United Nations General Assembly.

18 UNDP is bound by several international conventions, including the Beijing Declaration and Platform for Action (1995), Security Council Resolution 1325 on Women, Peace and Security, and the Hyogo Framework for Action (UNGA 2005).

19 UNDP, (2008b). "Gender Equality Strategy; UNDP, 2018." Gender Equality Strategy, 2018-2021; UNDP, 2014. "Gender Equality Strategy, 2018-2021.”

20 In Honduras, for example, UNDP is the key agency working on disaster risk reduction. Recent efforts include support to the Ministry of Planning in developing a national strategy for mainstreaming disaster risk reduction. UNDP has focused on linking disaster risk reduction planning at the municipal, regional and national levels.

21 A sizable percentage of major droughts during 2014-2018 globally occurred in Africa, impacting 15 LDCs severely. At least 13 LDCs in Africa are facing two consecutive droughts that will affect the livelihoods of over 30 million people: Angola, Burundi, Djibouti, Eritrea, Ethiopia, Lesotho, Madagascar, Mozambique, Rwanda, Somalia, Sudan, Uganda and the United Republic of Tanzania. In Asia, Cambodia, Myanmar and TimorLeste have been affected by drought. Some of these countries also face other weatherrelated challenges, including floods in Mali, Mozambique, South Sudan and Sudan.

22 For example, villages that participated in the programme had fewer casualties during the 2004 Indian Ocean tsunami.

\section{References}

Beck, T. et al. Humanitarian Action: Improving Monitoring to Enhance Accountability and Learning, London, Active Learning Network on Accountability and Performance in Humanitarian Action, 2003.

Benson, C. and E.J. Clay, 'Understanding the economic and financial impacts of natural disasters, disaster risk management', Series paper \# 4, World Bank, Washington, DC, 2004.

Bhatt, M., 'Gender and Disaster: Perspectives on women as victims of disasters', Discussion paper India, Disaster Mitigation Institute, Ahmedabad, 2005.

Chibber, A. and R. Laajaj, 'Disasters, climate change and economic development in SubSaharan Africa: Lessons and directions', Journal of African Economies, 17 (2): 7-49, 2008.

Daniell, J.E., J.E. Daniell, A.Vervaeck, B. Khazai and F.Wenzel, Worldwide CATDAT Damaging Earthquakes Database in conjunction with Earthquake-report.com - Presenting Past and Present Socio-Economic Earthquake Data, WCEE, Lisboa, 2012.

Evaluation Office of UNDP (EO), 'Assessment of Development Results: Nicaragua', New York, 2007.

EO, 'Assessment of Development Results: Tajikistan', New York, 2009. EO, UNDP, New York.

EO, 'Evaluation of UNDP Contribution to Environmental Management for Poverty Reduction: The Poverty-Environment Nexus', New York, 2010a. EO, UNDP, New York.

EO, 'Evaluation of UNDP Contribution to Disaster Prevention and Recovery', New York, 2010b. EO, UNDP, New York.

Harmeling, S., Global Climate Risk Index 2009:Weather-Related Loss Events and Their Impact on Countries in 2007 and a Long-Term Comparison, Briefing paper, German Watch, Berlin, 2009.

Houghton, R. et al., ALNAP Review of Humanitarian Action in 2003: Field Level Learning, London, Active Learning Network on Accountability and Performance in Humanitarian Action, 2004. 
Inter-Agency Standing Committee, The Inter-Agency Standing Committee Cluster Approach in Practice Countries and Implementation, November, New York 2009.

International Federation of Red Cross and Red Crescent Societies, 'World disasters report 2009: Focus on early warning', Geneva, 2009.

Intergovernmental Panel on Climate Change (IPCC), Climate change 2007: Synthesis report contribution of Working Groups I, II and III to the Fourth Assessment Report of the Intergovernmental Panel on Climate Change, Geneva, 2008.

Neumayer, E. and T. Plümper, 'The gendered nature of natural disasters: The impact of catastrophic events on the gender gap in life expectancy, 1981-2002', London School of Economics and Political Science and Department of Government, University of Essex, and MaxPlanck Institute of Economics, 2007.

Organization for Economic Co-operation and Development (OECD), 'DAC (Development Assistance Committee) Guiding Principles for Aid Effectiveness, Gender Equality and Women's Empowerment', Paris, December 2008.

Prasad, N. et al., Climate Resilient Cities: A Primer on Reducing Vulnerabilities to Disasters, Washington, DC, World Bank 2009.

Rodriguez, J., F.Vos, R. Below and D. Guha-Sapir, 'Annual disaster statistical review 2008: The numbers and trends', Centre for Research on the Epidemiology of Disasters, Brussels, 2009.

Sachs, J., Investing in Development: A Practical Plan to Achieve the Millennium Development Goals in 2005, New York, United Nations Millennium Project, 2005.

Solomon, S. et al., eds., Climate Change 2007:The Physical Science Basis. Cambridge, Cambridge University Press, 2007.

Telford, J. and J. Cosgrave, Joint Evaluation of International Response to Indian Ocean Tsunami, London, Tsunami Evaluation Coalition, 2006.

Telford, J. and J. Cosgrave, 'Responding to earthquakes 2008: Learning from earthquake relief and recovery operations', London, ALNAP and ProVention Consortium, 2008.

United Nations (UN), The Millennium Development Goals Report 2010, New York, 2010. UN, New York.

United Nations Development Programme (UNDP), Reducing Disaster Risk: A Challenge for Development, New York, 2004.

UNDP, Beyond Scarcity: Power, Poverty and the Global Water Crisis, Human Development Report, New York, 2006.

UNDP, Fighting Climate Change: Human Solidarity in a Divided World, Human Development Report 2007-2008, New York, 2007.

UNDP, 'The eight-point agenda: Practical, positive outcomes for girls and women in crisis', 2007b, available at http://www.undp.org/cpr/we_do/8_pa.shtml.

UNDP, 'Empowered and Equal: Gender Equality Strategy, 2008-2011', New York, 2008, available at http://www.undp.org/women/docs/Gender-Equality-Strategy-2008-2011.pdf, accessed January 242014.

UNDP Executive Board, Role of UNDP in Crisis and Post-Conflict Situations, First regular session 2001, UN document DP/2001/4, New York, UNDP, 2001.

UNDP Executive Board, 'Multi-Year Funding Framework 2000-2003', Second regular session, UN document DP/1999/30, New York, 1999.

UNDP Executive Board, 'Second Multi-Year Funding Framework', 2004-2007, UN document DP/2003/32, New York, 2003.

UNDP Executive Board, 'Strategic Plan 2008-2011: Accelerating Global Progress on Human Development', Second regular session, UN document DP/2007/43, New York, 2007.

UNDP, 2015. Reducing Disaster Risk, A Challenge for Development. https://www.undp.org/ content/undp/en/home/librarypage/crisis-prevention-and-recovery/reducing-disasterrisk--a-challenge-for-development.html 
United Nations International Strategy for Disaster Risk Reduction (UNISDR), 2009 Global Assessment Report on Disaster Risk Reduction: Risk and Poverty in a Changing World, Geneva, 2009a.

UNISDR, 'Applying Disaster Risk Reduction for Climate Change Adaptation: Country Practices and Lessons', Geneva, 2009.Making Disaster Risk Reduction Gender-Sensitive: Policy and Practical Guidelines, Geneva, 2009.

UNISDR/EM-DAT: CRED International Disaster Database, available at http://www.unisdr. org/disaster-statistics/occurren, accessed 4 September 2013.

UNGA, Implementation of the International Strategy for Disaster Risk Reduction, Report of the Secretary-General to the UN General Assembly, UN document A/63/351, United Nations, New York, 2008.

UNGA, Implementation of the international strategy for disaster reduction, Report of the SecretaryGeneral, UN Document A/63/351, New York, 2012.

United States National Oceanic and Atmospheric Administration, National Hurricane Center (NOAA/NHC), available at http://www.nhc.noaa.gov/aboutsshs.shtml, accessed 11 September 2013.

Wisner, B., B. Piers, T. Cannon and I. Davis, At Risk: Natural Hazards, People's Vulnerability and Disasters, London, Routledge, 2004.

World Food Programme (WFP), International Federation of the Red Cross and Red Crescent Societies (IFRCRC) and the UN Office for the Coordination of Humanitarian Affairs (OCHA), 'Addressing the humanitarian challenges of climate change: Regional and national perspectives', preliminary findings from the IASC regional- and national-level consultations, 2009.s 